\title{
Indoor Background Ionizing Radiations in Selected Premises in Mombasa County, Kenya
}

\author{
Richard O. Oduor ${ }^{1^{*}}$ \\ Senior Lecturer, Department of Biochemistry, Microbiology \& Biotechnology, Kenyatta University, Nairobi, Kenya ${ }^{1}$
}

\begin{abstract}
Ionizing background radiation was recorded from 390 residential premises within 12 estates in Mombasa County, Kenya, to determine the levels of indoor ionizing radiation relative to the WHO recommended annual threshold. Most premises revealed increased levels of radiations with the highest level of ionizing radiation recorded in Mkomani, indicating a $61 \%$ deviation from WHO recommended standard. The results reported in this study reveal a possible environmental hazard emanating from exposure to indoor ionizing radiations. Whereas other activities including those involving hydrocarbon industry can elevate the ionizing radiation levels of the environment, this study recommends a baseline survey of the level of ionizing radiation of quarries around Mombasa county in order to determine the extent to which quarry stones contribute to rising levels of ionizing radiations in the environment in Mombasa county.
\end{abstract}

Keywords: Ionizing Radiation, premises, cancer, stones

\section{INTRODUCTION}

When cells are exposed to ionizing radiations such as x-rays and gamma rays, given off by radioactive materials such as alpha particles, beta particles, and neutrons, they undergo genetic mutations, which may result in several health hazards including cancer [1]. These ionizing radiations occur in trace levels in rocks as naturally occurring radioactive materials. Ionizing radiations comprises subatomic particles, ions or atoms and electromagnetic waves on the short wavelength end of the electromagnetic spectrum. They are highly energetic and when they pass through a material, they deposit enough energy that can lead to breakage of molecular bonds and displacement of electrons from atoms. The electron displacement results in ions that cause changes in human cells [2]. This leads to DNA mutations that cause cancer or cell death. World Health Organization recommends that the annual exposure to background ionizing for the general public should not exceed $1 \mathrm{mSv}$ because the risk of cancer increases with the increase in the duration of radiation exposure. The extent of cell damage is directly related to the dose of radiation it receives [3]. In Kenya, and particularly Mombasa county, most permanent buildings are usually constructed using sand and underground stones mined from rocks and river beds, yet these materials have not been radio-profiled to determine the levels of embedded radionuclides present in these stones and sand [4]. Further, the risk of cancer from exposure to ionizing background radiation increases as the dose of radiation increases [5]. This study, therefore, sought to determine the levels of indoor ionizing radiation in selected premises in Mombasa County, Kenya, with a view to profiling the extent of deviation from the recommended thresholds.

\section{MATERIALS AND METHODS}

2.1 Sampling, Data Collection and Analysis: The study sampled 390 premises from 12 estates namely: Blue Estate, Central Old Town, Ethopia Estate, Gishaga, Green Estate, Kiembeni, Mkomani, Red Estate, Salama, Shika Adabu, Viemani and VOK. Radiation measurements were captured with the radiation meter held away from sampled surfaces in all the areas. In every premise/unit, eight indoor measurements were recorded. The readings were captured in milliRoentgew per hour $(\mathrm{mR} / \mathrm{h})$. The readings were recorded in a work sheet and entered in Microsoft excel spreadsheet for analysis. Radiation readings were converted from hours to years under the assumption that humans live in their premises for 24h a day. An occupancy factor (OF) of 0.8 outlined by UNSCEAR in 1988, which represents the proportion of the total time during which an individual is exposed to a radiation field was included in the equation. When converting the indoor readings to annual equivalent doses in $\mathrm{mSv} / \mathrm{y}$ for the premises, the following equation was used.

\section{$E_{1}=X \times 8760 \times 0.8 \times 0.01 \times 1.7$}

$\mathrm{E}_{1}$ is the annual equivalent dose rate in $\mathrm{mSv} / \mathrm{y}$. 8760 is the annual conversion factor in hours/year. 0.01 is the conversion of $\mathrm{mR}$ to $\mathrm{mSv}$
$\mathrm{X}$ is the indoor meter reading in $\mathrm{mR} / \mathrm{h}$.

0.8 is the indoor occupancy factor

1.7 is the calibration factor. 


\section{International Advanced Research Journal in Science, Engineering and Technology}

Vol. 5, Issue 11, November 2018

The data was subjected to descriptive statistics and were expressed as Means \pm SEM. One way ANOVA was used to test the significance within the premise clusters at 95\% confidence level. Data was further subjected to Turkey's post hoc for pairwise comparison and separation of means. Minitab version 17.0 was used to determine the significant relationships between the radiations from different premises. The findings were presented through tables that showed levels of mean radiation levels between premises and their differences in statistical significance. The results were further computed relative to the recommended WHO annual dose reference of $1 \mathrm{mSv}$. The percentage deviations was calculated by getting the percentage of the difference of the annual reading from the WHO standard.

\section{RESULTS AND DISCUSSIONS}

Of the 12 estates sampled, the highest level of ionizing radiation was recorded in Mkomani with a $61 \%$ deviation from WHO recommended standard. This was followed by Gishaga (44.2\%), then VOK (38.3\%) (Table 1). The least level of ionizing radiation was recorded in Shika Adamu with only $0.8 \%$ deviation the WHO recommended threshold (Table 1). There was no statistical significance in levels of ionizing radiation between the Mkomani and Gishaga ( $\mathrm{p} \leq 0.05)$. Likewise, Viemani, Central Old Town, Salama, VOK, Blue Estate, Kiembeni, Red Estate, Ethopia Estate and Green Estate did not show any statistical significance in the levels of ionizing radiations (Table $1, \mathrm{p} \leq 0.05$ ). However, Shika Adabu and Mkomani showed statistical significance in the levels of the ionizing radiation (Table 1, $\mathrm{p} \leq 0.05$ ).

Table 1: Annual levels of ionizing radiation in premises in Mombasa County

\begin{tabular}{lll}
\hline Estate & Annual Indoor Reading $(\mathbf{m S v})$ & $\begin{array}{l}\text { Percentage deviation from WHO } \\
\text { recommended standard }\end{array}$ \\
\hline Shika Adabu & $1.008 \pm 0.041^{\mathrm{b}}$ & $0.8 \%$ \\
Viemani & $1.368 \pm 0.082^{\mathrm{ab}}$ & $36.8 \%$ \\
Mkomani & $1.610 \pm 0.331^{\mathrm{a}}$ & $61.0 \%$ \\
Central Old Town & $1.343 \pm 0.072^{\mathrm{ab}}$ & $34.3 \%$ \\
VOK & $1.383 \pm 0.058^{\mathrm{ab}}$ & $38.3 \%$ \\
Gishaga & $1.442 \pm 0.081^{\mathrm{a}}$ & $44.2 \%$ \\
Salama & $1.297 \pm 0.054^{\mathrm{ab}}$ & $29.7 \%$ \\
Blue Estate & $1.267 \pm 0.061^{\mathrm{ab}}$ & $26.7 \%$ \\
Kiembeni & $1.315 \pm 0.047^{\mathrm{ab}}$ & $31.5 \%$ \\
Red Estate & $1.275 \pm 0.048^{\mathrm{ab}}$ & $27.5 \%$ \\
Ethopia Estate & $1.294 \pm 0.055^{\mathrm{ab}}$ & $29.4 \%$ \\
Green Estate & $1.328 \pm 0.045^{\mathrm{ab}}$ & $32.8 \%$ \\
\hline
\end{tabular}

Values are expressed as Mean \pm SEM. Values followed by the same superscript are not significantly different ( $\mathrm{p} \leq 0.05$; One way ANOVA followed by Tukey's post hoc test)

Most premises sampled in Shika Adabu (54\%) were compliant and had less than zero percentage deviation from the WHO threshold, followed by $31 \%$ (Blue estate), then Salama (28\%) and lastly Gishaga (4\%) (Table 2). Whereas Gishaga showed the least proportion of percentage deviation below zero, it also had the highest number of premises (23\%) with deviations above $81 \%$.

Table 2: Number of premises (\%) and percentage annual deviation from WHO recommended exposure standard of ionizing radiation in selected estates around Mombasa County.

\begin{tabular}{|c|c|c|c|c|c|c|c|c|c|c|c|c|}
\hline 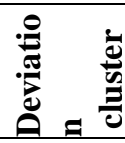 & 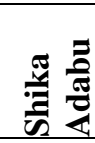 & 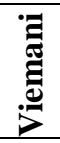 & 㿣 & 胥 & $\frac{1}{O}$ & 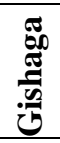 & 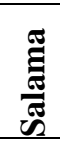 & 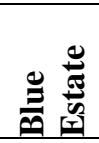 & है & 卷 & 苟 & 总 \\
\hline $0<$ & 54 & 21 & 10 & 17 & 12 & 4 & 28 & 31 & 14 & 9 & 11 & 16 \\
\hline $1-20$ & 35 & 12 & 35 & 26 & 15 & 39 & 14 & 17 & 20 & 37 & 29 & 18 \\
\hline $21-40$ & 4 & 25 & 25 & 20 & 31 & 13 & 14 & 17 & 34 & 29 & 34 & 26 \\
\hline $41-60$ & 7 & 17 & 15 & 17 & 23 & 17 & 24 & 20 & 17 & 11 & 11 & 24 \\
\hline $61-80$ & 0 & 8 & 5 & 13 & 7 & 4 & 10 & 9 & 6 & 9 & 9 & 6 \\
\hline $81>$ & 0 & 17 & 10 & 7 & 12 & 23 & 10 & 6 & 9 & 5 & 6 & 10 \\
\hline
\end{tabular}

Number of premises are in \%

When the total premises sampled in Mombasa were clustered to determine the overall deviation from the recommended threshold, only $19 \%$ showed percentage deviation less than zero with majority of the premises (24\%) clustering between 1-20 category (Table 3). 


\section{International Advanced Research Journal in Science, Engineering and Technology}

Vol. 5, Issue 11, November 2018

Table 3: Overall percentage annual deviation from WHO recommended standard of ionizing radiation in Mombasa County

\begin{tabular}{cc}
\hline Deviation cluster (\%) & Number of units (\%) \\
\hline $0<$ & 19 \\
$1-20$ & 24 \\
$21-40$ & 23 \\
$41-60$ & 18 \\
$61-80$ & 8 \\
$81>$ & 8 \\
\hline
\end{tabular}

The variation in the radiation levels shown in this study may be attributed to the difference in concentrations of naturally occurring radionuclides among the stones used in their building. Previous studies have shown that naturally occurring radionuclides become trapped in the earth's crust during the formation of the parent rocks [6] and end up in soils as part of rock cycle through weathering. Additional studies reveal that the radionuclides may show a distinct variation in the radiation level in any environment based on many factors such as geographical and local geology of the area studied [7]. The relatively high levels of ionizing radiations may be attributed to the fact that most permanent buildings in Mombasa County are constructed using stones mined from quarries which may excavate large amount of otherwise buried materials containing natural occurring radioactive materials onto the surface of the environment [8]

\section{CONCLUSION}

The results reported in this study reveal a possible environmental hazard emanating from exposure to indoor ionizing radiation from residential premises above the recommended thresholds guided by the WHO. Whereas activities of the hydrocarbon industry can elevate the ionizing radiation levels of the environment (Chad-Umoren and Briggs-Kamara 2010), a baseline survey of the level of ionizing radiation from quarry stones needs to be conducted to determine the extent to which quarry stones contribute to rising levels of ionizing radiations in the environment.

\section{ACKNOWLEDGMENT}

The author is grateful to the National Research Fund for funding this research

\section{REFERENCES}

[1]. Fletcher, O. and Houlston, R. S. Architecture of inherited susceptibility to common cancer. Nature Reviews Cancer 10, 353-361. doi:10.1038/nrc2840. 2010.

[2]. Environmental Protection Agency. Understanding Radiation 2009.

[3]. Environmental Protection Agency. Radiation Risks and Realities 2007

[4]. Ogola PE, Arika WM, Nyamai DW, Osano KO, achuonyo HO, Wambani JR, Lagat RC, Njagi SM, Mumenya SW, Koteng A, Ngugi MP, Oduor RO. Determination of background ionizing radiations in selected buildings in Nairobi County, Kenya. Journal of Nuclear Medicine and Radiation Therapy 7:29.doi:10.4172/2155-9619.1000289. 2016

[5]. Walker, C. L. and Ho, S. Developmental reprogramming of cancer susceptibility. Nature Reviews Cancer 12, 479-486. doi:10.1038/nrc3220. 2012

[6]. Florou, H. andKritidis, P. Gamma radiation measurements and dose rate in the coastal areas of a volcanic island, Aegean Sea, Greece. Radiation Protection Dosimetry, 45(1-4), 277-279. 1992

[7]. Gbadebo, A. M. Natural Radionuclides Distribution in the Granitic Rocks and Soils of Abandoned Quarry Sites, Abeokuta, South western Nigeria AM Gbadebo. Asian Journal of Applied Sciences, 4(2), 176-185. 2011.

[8]. Gbadebo, A. M., Ayedun, H. and Okedeyi, A. S. Assessment of radiation Level within and around Stonebridge Quarry site, km 22 Lagos Ibadan Express Way, Southwest Nigeria. Environmental Research Journal, 5 (2): 25-30. 2011.

[9]. Chad-Umoren, Y. E. and Briggs-Kamara, M. A. Environmental ionizing radiation distribution in rivers state, Nigeria. Journal of Environmental Engineering and Landscape Management, 18(2), 154-161. 2010

[10]. Chad-Umoren, Y. E. and Obinoma, O. Determination of Ionizing Radiation Level of the Main Campus of the College of Education, Rumuolumeni, Rivers State, Nigeria. Int'l Journal of Environmental Issues, 5(1\&2), 5-10. 2007 